\title{
Surface deformation detected by the space-observed small baseline SAR interferometry over permafrost environment in Tibet Plateau, China
}

F. Chen ${ }^{1,2}$ and H. Lin $^{2}$

${ }^{1}$ Center for Earth Observation and Digital Earth, Chinese Academy of Sciences, No. 9 Dengzhuang South Road, Haidian District, Beijing 100094, China

${ }^{2}$ Institute of Space and Earth Information Science, The Chinese University of Hong Kong, Shatin, N.T., Hong Kong, China

Received: 8 August 2012 - Accepted: 10 September 2012 - Published: 24 September 2012 Correspondence to: H. Lin (huilin @cuhk.edu.hk)

Published by Copernicus Publications on behalf of the European Geosciences Union.

Surface deformation monitoring by InSAR over Tibet permafrost regions

F. Chen and H. Lin

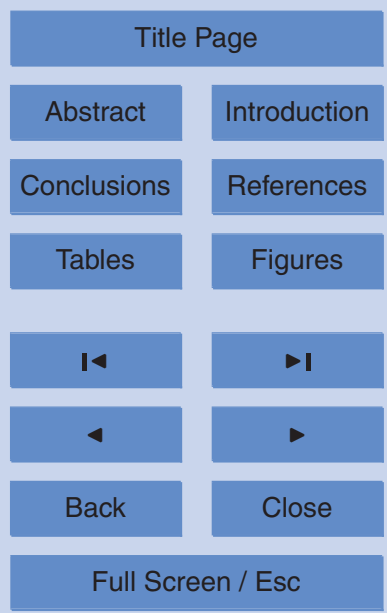

Printer-friendly Version

Interactive Discussion 


\section{Abstract}

The evolution of permafrost and the active layer is highly related to climate change because of its feedback effects involving water and carbon storage. In this study, we firstly examined the relationship of regional water balance, geomorphological process

5 and anthropogenic activities by means of Small Baseline Synthetic Aperture Radar Interferometry (SB-InSAR) to monitor the surface movements overlaid on the permafrost of Tibet Plateau (TP), China, using 3.5-yr observation span of L-band ALOS PALSAR data (June, 2007 to December, 2010). The estimated displacements (primarily in the range of $-30 \mathrm{~mm} \mathrm{yr}^{-1}$ to $30 \mathrm{~mm} \mathrm{yr}^{-1}$ ) and time-series implied evolutions of the 10 active layer and permafrost beneath. The motion trend along slopes was complicated, and thus interdisciplinary interpretations were required. Water level variations of inland lakes were then detected, although further investigations were required for validation. Anthropogenic influences on this frail permafrost environment were significant, proved by the remarkable surface settlement along the embankment of Qinghai-Tibet Railway.

15 Consequently, it is crucial and necessary to monitor this arid and cold plateau owing to the combination of climate change, geo-hazards prediction as well as the regional sustainable development.

\section{Introduction}

The Tibet Plateau (TP), recognized as the third pole of Earth, has the largest permafrost extent outside the polar region (Chen et al., 2012b). Permafrost is sensitive to global warming, resulting in significant influences on regional water balance, carbon cycle and engineering constructions. TP, known as the Asia water tower, is the source region of many major rivers in Asia (Immerzeel et al., 2008). The perennial flow of those rivers largely relies on the constant flux from glaciers melting. Approximately $23-48 \%$ of the total global soil carbon pool is stored in permafrost regions in the world (Guo and Macdonald, 2006). Alpine permafrost in TP bears a greater organic carbon pool than

\section{Surface deformation monitoring by InSAR over Tibet permafrost regions}

F. Chen and $\mathrm{H}$. Lin

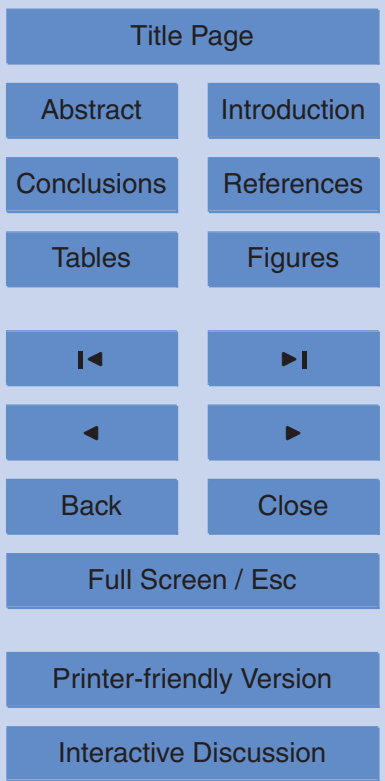


do grassland soils in other regions of China (Wang et al., 2008). Thus carbon emission from permafrost has been highly concerned when it thaws under global warming (Monastersky, 2011). The active layer overlaid on permafrost intends to be instable primarily determined by the frost heave and thaw settlement. As the development of 5 this remote plateau, the anthropogenic activities, such as expansive natural resource exploitation and tourism, have introduced external pressures to deteriorate the local environment. All issues described above are closely correlated with the evolution of the active layer as well as permafrost (growth or degradation).

As the highest terrestrial unit, abundance of studies has been conducted in TP be-

cause of its significance for global and regional sustainable development, including climate change and carbon emission (Liu et al., 2009; Wu et al., 2010), tectonics and earthquake (Ismail-Zadeh et al., 2007; Loveless and Meade, 2011; Qiao et al., 2011), water balance (Niu et al., 2011; Wang et al., 2009a,b) and permafrost environment (Jin et al., 2008; Yang et al., 2004). However, the estimation of surface movements 15 over permafrost environment, particularly in TP, using spaceborne Synthetic Aperture Radar Interferometry (InSAR) (Liu et al., 2010, 2012; Rykhus and Lu, 2008; Short et al., 2011) is still inadequate. Differential InSAR (DInSAR) (Massonnet et al., 1993), one of the quantitative remote sensing technologies, has proved to be effective for ground surface motion detection by measuring the phase difference of two or multitemporal SAR acquisitions (Chen and Lin, 2011). Its recent development results in the occurrence of Multi-Temporal SAR Interferometry (MT-InSAR), which mitigates the intrinsic limitations of the traditional DInSAR (spatial-temporal decorrelation as well as atmospheric disturbance); and thus is capable of deriving surface motion rates with millimetric accuracy using large datasets over the same scene. In general, MT-InSAR can be divided into two main categories, including Persistent Scatterer (PS) (Ferretti et al., 2000; Hooper et al., 2004) and Small Baseline InSAR (SB-InSAR) (Berardino et al., 2002; Chen et al., 2010, 2012a; Jiang et al., 2011; Lanari et al., 2004; Lin et al., 2011). The former concentrates on the phase analysis of PS points using single reference interferogram formation; in contrast, the alternative prefers to extract information

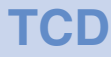

6, 4071-4099, 2012

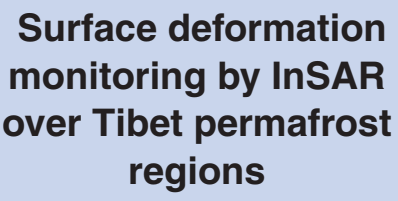

F. Chen and H. Lin

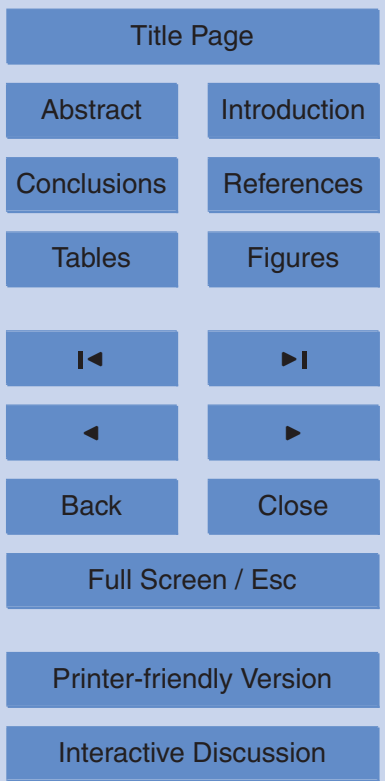


from distributed scatterer (DS) points with the aid of multi-references interferogram formation based on the small baseline constraint.

The past investigation demonstrated that, in the permafrost environment of TP, the DS points are prevalent excepted for the artificial structures, e.g. the embankment of 5 Qinghai-Tibet Railway (QTR) (Chen et al., 2012b). Consequently, in order to extract information as much as possible, the SB-InSAR is introduced for the evolution analysis of the active layer and permafrost. In total, 19 L-band ALOS PALSAR SLC images (acquired from June 2007 to December 2010) are employed to cover the Beiluhe experimental site, Qinghai, China. The subsequent sections will be organized as follows: in

10 Sect. 2, the study site and data are firstly described. Then, a re-call SB-InSAR methodology and its corresponding procedures are shown in Sect. 3 for easily understanding. After that, the SB-InSAR derived results are shown and then interpreted in Sect. 4. Taking the Gulug Co inland lake, natural slopes and the QTR as instances, Sect. 5 shows the discussion of surface displacements with respect to permafrost environments, geo15 morphological processes as well as anthropogenic activities. Finally, some conclusions are drawn.

\section{Study area and datasets}

For the easy accessibility and available ground-based measurements, the Beiluhe, Qinghai, China is selected as the experimental site (see Fig. 1), approximately ex20 tending from $92^{\circ} 16^{\prime}$ to $93^{\circ} 01^{\prime} \mathrm{E}$ and from $34^{\circ} 05^{\prime}$ to $34^{\circ} 55^{\prime} \mathrm{N}$. The temporal averaged amplitude SAR image in Fig. 1 shows the study site coverage with a spatial extent of $63 \times 45 \mathrm{~km}^{2}$ approximately. The topography of this site is composed by upland in the middle section in NW-SE direction represented by Fenghuo Mount, Ri'achi Mount; and mild terrain in the northeast and southwest represented by Beiluhe valley and 25 Erdaogou valley. Its high elevation (from 4500 to $5200 \mathrm{~m}$ ) causes an arid continental climate with annual precipitation ranging from 300 to $400 \mathrm{~mm}$. The seasonality of climate is heavily influenced by the Southeastern Asian monsoons. Most precipitation

\section{Surface deformation monitoring by InSAR over Tibet permafrost regions}

F. Chen and H. Lin

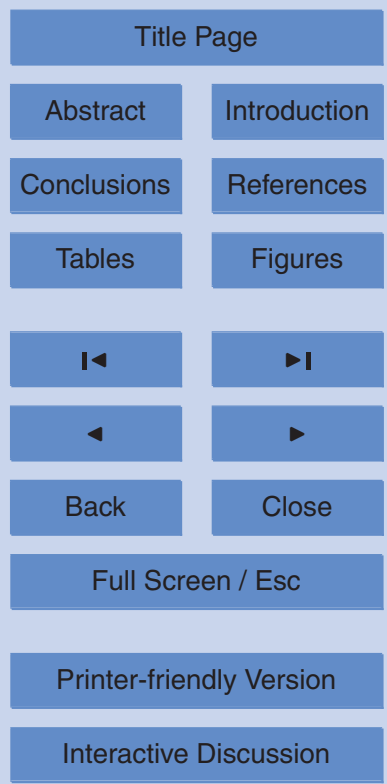


arrives during the months of June to August, in the form of very heavy rains, and the remaining in the form of snow or hail, generates snow cover during the freezing period (from September to April of next year), particularly in mountainous regions. The mean annual air temperature here is as low as about $-3.8^{\circ} \mathrm{C}$. Warm and ice-rich per5 mafrost (WIRP) is well developed in the above two valleys with mild terrain and high soil moisture. For instance, the ground ice extends to a depth of 2.0-8.0 m under the natural ground surface in the Beiluhe valley (Zhang et al., 2010). From the amplitude image, it is clear that the QTR runs from the northeast to the south due to its strong backscattering compared with its surrounding features, as marked by the pink lines (the 10 dotted section indicates the Fenghuo Mount Tunnel). An inland lake, so-called Gulug Co, locates in the Erdaogou valley, as marked by the red arrow in Fig. 1. Owing to the low-lying alluvial terrain, its water supply comes from the runoff primarily determined by the surface flow accumulation and the snow-ice melting of nearby mountains in warm and rainy seasons.

1519 ALOS PALSAR images acquired with ascending orbit, from June 2007 to December 2010, were used in this study, as listed in Table 1. The ALOS PALSAR data were obtained from the Japan Aerospace Exploration Agency (JAXA), and collected with a nominal radar look angle of 34.3 degrees. The dataset is comprised of two modes with the same center frequency of the range bandwidth, including 9 scenes of Fine Beam Single polarization (FBS, $28 \mathrm{MHz}$ ), and 10 scenes of Fine Beam Dual polarization (FBD, $14 \mathrm{MHz}$ ). The pixel spacing of $\mathrm{FBS}$ is $4.68 \mathrm{~m}$ in range direction and $3.17 \mathrm{~m}$ in azimuth direction, compared to $9.36 \mathrm{~m}$ by $3.17 \mathrm{~m}$ of FBD. In general, ALOS PALSAR has two advantages for the TP region monitoring: firstly, PALSAR works with a longer wavelength (L-band, $23.6 \mathrm{~cm}$ ), enabling to better penetrate vegetation and resulting in high quality interferograms; secondly, the ground resolution of PALSAR (8 $\mathrm{m}$ of FBS and $16 \mathrm{~m}$ of $\mathrm{FBD}$ ) is higher than other median resolution data (e.g. 25-30 m of ERS-1/2 and Envisat ASAR), and thus preserves more detailed information. The 3-arcsecond ( $90 \mathrm{~m}$ ) Shuttle Radar Topography Mission (SRTM) DEM data from the United States Geological Survey (USGS) were used for topographic phase estimation at the first step,

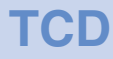

6, 4071-4099, 2012

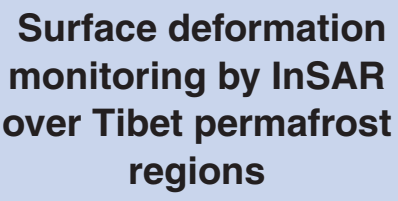

F. Chen and $\mathrm{H}$. Lin

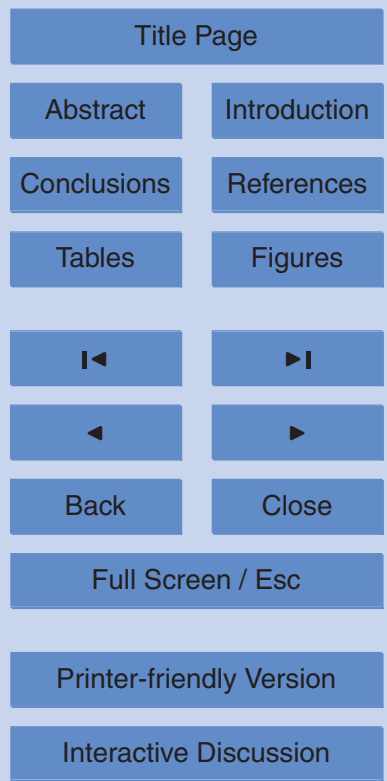


and then for geocoding InSAR products (transforming Range-Doppler coordinates into Universal Transverse Mercator map geometry system).

\section{Small baseline InSAR procedures}

From the previous study (Chen et al., 2012b), we found that the seasonal effect and 5 non-linear surface motions in TP are evident. We hypothesize the surface deformation driving-force of TP is analogous to Alaska, USA as described by Liu et al. $(2010,2012)$, that is, the surface movements are caused by two primary components: seasonal displacement by thaw settlement or frost heave of the active layer, and the secular subsidence due to thawing of ice-rich permafrost near the permafrost table. Our past field 10 investigation indicated that apart from artificial structures, e.g. QTR, the DS features are dominant over TP region. Consequently, in order to extract the surface motions (the combination dynamics of permafrost and the overlaid active layer), in this study, the SB-InSAR method (Berardino et al., 2002) is introduced taking advantages of its capability of dense DS extraction.

15 In the SB-InSAR approach, interferogram formation is controlled by thresholds of spatial-temporal baselines as well as the Doppler centroid difference. In this study, only the spatial-temporal baselines are applied (small than $3800 \mathrm{~m}$ spatially and 368 days temporally), because of the negligible difference of Doppler centroids (see Table 1). The common $\mathrm{HH}$ polarization data from two fine modes are used for interferometric processing after the FBS data are doubly down-sampled in range direction. The multilooking with 1 by 5 in range and azimuth direction are used to derive InSAR products with approximately $16 \mathrm{~m}$ ground resolution. Then initial 67 differential interferograms are generated (note that the topographic and flat earth phase components have been removed). The Minimum Cost Flow (MCF) (Colesanti, 1998) is used for phase unwrapping. After careful checking by manual, another 7 low-quality interferograms (including phase unwrapping errors or significant ionospheric component of atmosphere) are discarded to derive 60 final interferograms for further motion estimation and time series
6, 4071-4099, 2012

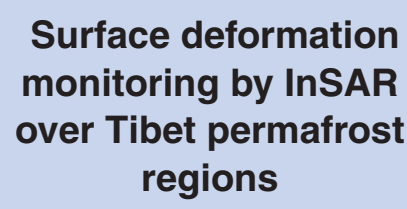

F. Chen and $\mathrm{H}$. Lin

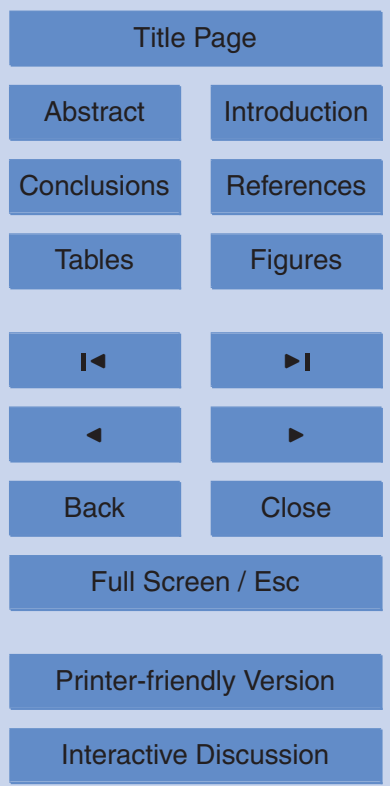


analysis, as illustrated in Fig. 2. It is clear that the PALSAR perpendicular baseline is correlated with the time of acquisition (Samsonov, 2010), implying the suitability of SBInSAR method for the TP investigation in the case of isolated interferogram subsets in time.

5 In general, the implementation of SB-InSAR is comprised of two main steps. The first step is the estimation of low-pass displacement and residual height using a preferred cubic displacement model. The Coherent Point (CP) candidates are characterized by a high average spatial coherence. The $\mathrm{CP}$ with the maximum value is selected as the reference point. In this step, the Least Squares (LS) algorithm is applied for pa10 rameters inversion. The second step is concentrated on the displacement time series retrieval and atmospheric artifacts isolation. That is, (a) we derive residual phases by subtracting the low-pass component signatures (derived in the first step) from the original differential interferograms; (b) we unwarp residual phases, and then calculate the improved interferogram phases by adding back the previous low-pass components; 15 (c) we estimate motion time series using the Singular Value Decomposition (SVD) algorithm; (d) we derive refined residual phases by subtracting the low-pass deformation component from the motion time series; (e) we estimate atmospheric artifact phases using temporal-spatial filters (firstly a temporal high-pass and then a spatial low-pass); (f) we derive the final deformation components after the atmospheric artifacts isolation. 20 Note that final CPs are further identified by the temporal coherence with respect to a defined displacement model.

\section{Results, validation and monitoring interpretation}

Using the two thresholds ( 0.4 average spatial coherence and 0.6 temporal coherence), the SB-InSAR derived surface displacement rates in line-of-sight (LOS) over Beiluhe 25 TP region are illustrated in Fig. 3. The negative motion rates' sign is indicative of an increasing distance with time away from the satellite (subsidence); and positive sign represents an uplift motion. The result indicates that the surface motion caused by the

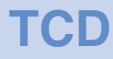

$6,4071-4099,2012$

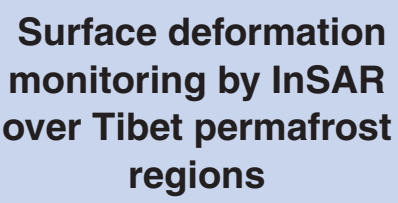

F. Chen and $\mathrm{H}$. Lin

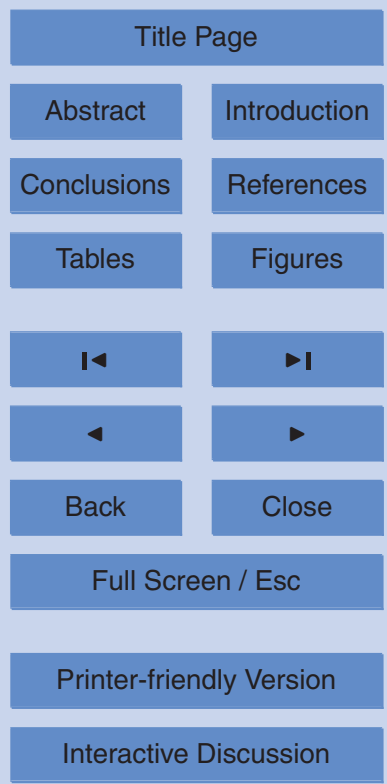

Interactive Discussion 
seasonal variation of the active layer and secular subsidence of ice-rich permafrost table is evident, primarily in the range of $-30 \mathrm{~mm} \mathrm{yr}^{-1}$ to $30 \mathrm{~mm} \mathrm{yr}^{-1}$ in the $3.5-\mathrm{yr}$ observation span (from June 2007 to December 2010). The InSAR-derived results have been validated by leveling data located nearby the Fenghuo Mount Tunnel frontier 5 (marked by the cross in Fig. 3). The two different types of data demonstrate consistent motion trends with absolute discrepancies varying from 0.5 to $4 \mathrm{~mm} \mathrm{yr}^{-1}$. There are totally $8025313 \mathrm{CPs}$ over the study site with approximately $63 \times 45 \mathrm{~km}^{2}$, that is, $2800 \mathrm{CPs} \mathrm{km}^{-2}$. The high spatial density of CPs is determined by following two aspects. Firstly, PALSAR has a long wavelength, resulting in high penetration and coher10 ence preservation, particularly in non-urban areas, e.g. TP. Second, the small baseline strategy is introduced in interferometric formation, and thus high-quality interferograms can be guaranteed, resulting in high spatial density of CP candidates and then the final CPs.

In order to interpret the surface motion trends (magnitude and direction), the rela15 tionship between SAR imaging geometry (ascending with 34.3 degree incidence angle in this case) and the surface displacement is analyzed (see Fig. 4). In the upper or middle section of slopes, the rotational motions from both sides demonstrate consistent movements, that is, frost heave as uplifts in LOS and thaw settlement as subsidence in LOS, as marked by "a" , "aa" and "b", "bb". For the slope facing the satellite, the downslope movement of material on the steep section (angle of gradient $>34.3^{\circ}$ ) demonstrates as mild subsidence (marked by " $\mathrm{c}_{1}$ ") and on the medium section (angle of gradient $<34.3^{\circ}$ ) demonstrates as mild uplift (marked by " $\mathrm{c}_{2}$ "); in contrast, those two motion components both demonstrate as obvious subsidence on the backslope (see "cc"). Regarding to valley regions with flat terrain (the foot of slopes), the actual motion trend from both sides can be measured as uplift (marked by "d" and "dd", respectively) when the deposition or heave is dominant, and vice versa, measured as subsidence (marked by "e" and "ee", respectively) when the thaw settlement is prevalent.

From Fig. 3, it is clear that the majority of surface (60\% to $65 \%)$ is relatively stable, in the range of $-10 \mathrm{~mm} \mathrm{yr}^{-1}$ to $10 \mathrm{~mm} \mathrm{yr}^{-1}$. The majority of InSAR-detected uplifts in

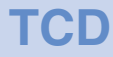

$6,4071-4099,2012$

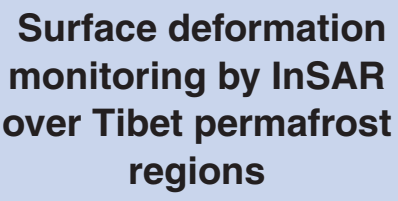

F. Chen and $\mathrm{H}$. Lin

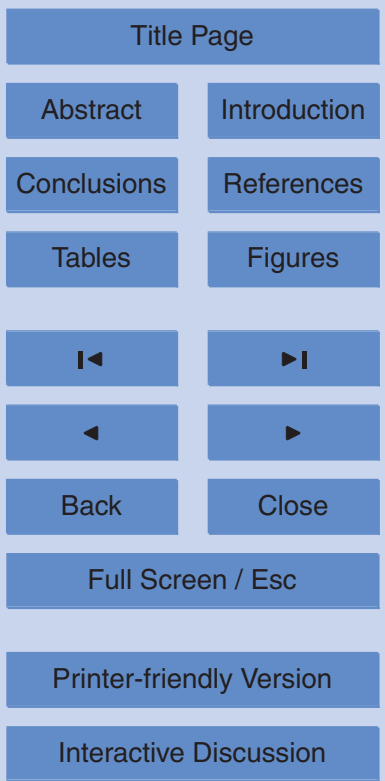


Fig. 3 are highly related to slopes processes (interpreted by the downward movements of " $\mathrm{C}_{2}$ " in Fig. 4) rather than permafrost or the active layer growth under climate warming trends. However, a few isolated uplifts occur with values larger than $20 \mathrm{~mm} \mathrm{yr}^{-1}$ mainly locating in mountainous areas, and the frost heave is dominant because of the low 5 temperature throughout of years. The remaining surface is presented as mild-severe subsidence, in the range of $-35 \mathrm{~mm} \mathrm{yr}^{-1}$ to $-10 \mathrm{~mm} \mathrm{yr}^{-1}$, corresponding mountainous slopes and mild-terrain WRIP regions. The causes for this phenomenon are primarily determined by the transitional movement of unconsolidated material on backslopes or surface thaw settlement overlaid on WRIP areas. It is evident that most of the areas with the strongest signals (positive or negative) are directly aligned with slopes, and thus we interpret that slope processes likely dominate more of the InSAR information than permafrost and the overlaid active layer activity in a relatively short 3.5-yr observation period.

Note that the tectonic motion in TP is not negligible, confirmed by the investigation of 15 Cavalie et al. (2008) and Loveless and Meade (2011). The nominally interseismic GPS velocities (calibrated by a stable Eurasian reference frame) in recent years demonstrate that the tectonic movement over Beiluhe section is around $15 \mathrm{~mm} \mathrm{yr}^{-1}$ in SW-NE direction (approximately perpendicular to the fight path of ALOS PALSAR), as highlighted by the pink rectangle in Fig. 5. This will introduce a global subsidence contribution in 20 LOS direction with values in the range of $-7 \mathrm{~mm} \mathrm{yr}^{-1}$ to $-8 \mathrm{~mm} \mathrm{yr}^{-1}$ in the Beiluhe site. However, as we known, the SB-InSAR results only measure the relative displacements compared with a local reference point, and thus this homogeneous bias is not taken into consideration when the study site coverage is much smaller than $500 \times 500 \mathrm{~km}^{2}$.

\section{Discussions}

25 Liu et al. (2010) found that the causes of surface deformation over permafrost regions are complicated. At local scales, the deformation could be controlled by local surface vegetation, soil deposits, water/ice content, active layer thickness, hydrological settings

\section{TCD}

$6,4071-4099,2012$

\section{Surface deformation monitoring by InSAR over Tibet permafrost regions}

F. Chen and H. Lin

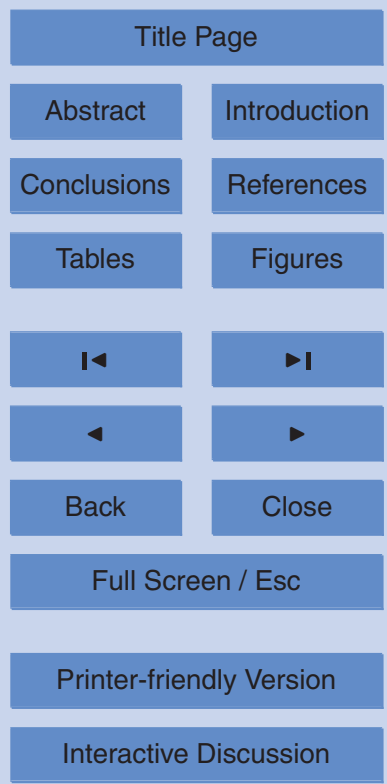


and etc. In other hand, the secular surface subsidence could be another driving-force due to thawing of ice-rich permafrost beneath the active layer under global warming. In this paper, the quantitative deformation discrimination of permafrost and overlaid active layer is out of this study scope (interested readers please refer to Liu et al., 2010, 5 2012); instead, the contributions to InSAR signals from hydrological, geomorphological process and anthropogenic activities will be further discussed.

\subsection{Gulug Co inland lake}

Gulug $\mathrm{Co}_{\mathrm{o}}$ is one of the largest inland lakes nearby Fenghuo Mount Tunnel frontier, which is located in the south-foot of Ri'achi Mount (also called as Erdaogou valley) 10 and fed by the surface runoff from rivers (Gouluchongqinma Co River in the west and Sangqia Co River in the south) or mountains nearby. Its water coverage and catchment area reach approximately 23.5 and $534 \mathrm{~km}^{2}$, respectively, when the a.s.l of lake equals to $4666 \mathrm{~m}$. The average water depth of Gulug Co is larger than $1.3 \mathrm{~m}$. The water level variation can be a sensitive indicator for the regional water balance related to the global warming (Xu et al., 2009), resulting in glacier melting and permafrost thaw degradation. Previous studies (Lu et al., 2005; Wdowinski et al., 2008) have proved that InSAR techniques are potential for water level variation detection in wetlands when the assumption of double-bounce refection holds, e.g. the dihedral scattering composed by the flat water and cliff shores (facing the satellite) in this study. A severe subsidence along a section of cliff lakeshore is detected by the SB-InSAR (the double-bounce comprised by flat water surface and cliff shoreline is prevalent), as highlighted by the red arrow in Fig. 6; in contrast, other sections with gentle lakeshore reveal stability (the surface motion along the shoreline is dominant because of the distributed scat25 terering mechanism). This phenomenon implies the promise of InSAR approaches in water level change detection. For instance, in this study, we detected a decreased trend $\left(-50 \mathrm{~mm} \mathrm{yr}^{-1}\right.$ to $\left.-30 \mathrm{~mm} \mathrm{yr}^{-1}\right)$ of Gulug Co inland lake in the 3.5-yr observation span (from June, 2007 to December, 2010) in case of the signature separates

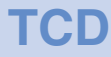

$6,4071-4099,2012$

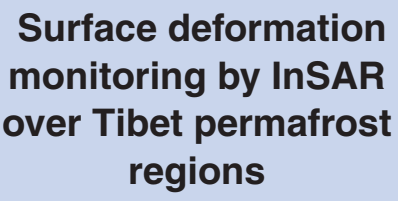

F. Chen and $\mathrm{H}$. Lin

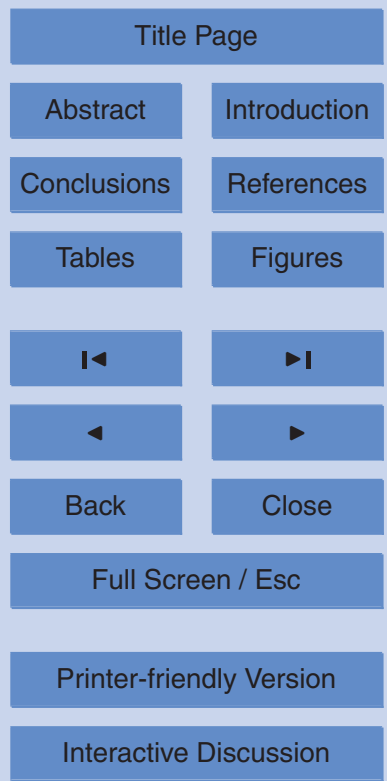

Interactive Discussion 
from ground movements. Apart from the surface runoff as well as the permafrost and overlaid active layer ice-content melting, the water feed of this lake from glacier/snow melting is negligible (no glacier exists around this area). Consequently, the reason for the slight decrease of water level could be either the overall increased evaporation or 5 negative difference of water budget between precipitation and evaporation, because the evaporation rate is about 2-3 times higher than the precipitation rate in this area (Zhang et al., 2011). Generally, the inland lake level variation in TP has close relationship with the regional water balance, particularly under global warming and climate change. However, further investigation is required due to following two aspects. Firstly, 10 the InSAR-detected subsidence dimension is too regional to separate other influence factors, e.g. regional ground instability caused by surface erosion. Secondly, the InSAR measurements need to be cross-compared with other measurements from field works or altimeter satellites (e.g. ICESat), in order to prove the feasibility of InSAR approaches in monitoring the water level variation of inland lakes.

\subsection{Mountainous slopes}

Past field investigations indicated that the land cover in the Beiluhe site is relatively sparse, scattered by alpine meadows in flat valleys owing to the high soil moisture. In the TP arid and cold environment, the mountains are exposed by rocks or weathered deposits. Those covers are unconsolidated because of heavily decomposed rocks as well as sparse vegetation. Consequently, when the shearing force (triggered by the surface overflow and shallow groundwater flow) exceeds a threshold, a surficial landslide occurs. Fig. 7a shows the surface deformation field over a mountain region nearby Fenghuo Mount. Referring to relief-shaded DEM in Fig. 7b, it is clear that uplifts in LOS direction are dominated in the upper-middle section (slope gradient $>34.3$ degree) of frost heave (interpreted by "a" and "aa" in Fig. 4) can be another cause although the corresponding contribution is low due to the global warming trend. In the middle-lower section (slope gradient $<34.3$ degree), the downward transitional movement (parallels to

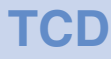

6, 4071-4099, 2012

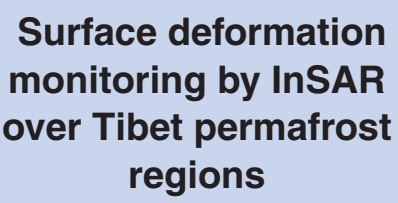

F. Chen and $\mathrm{H}$. Lin

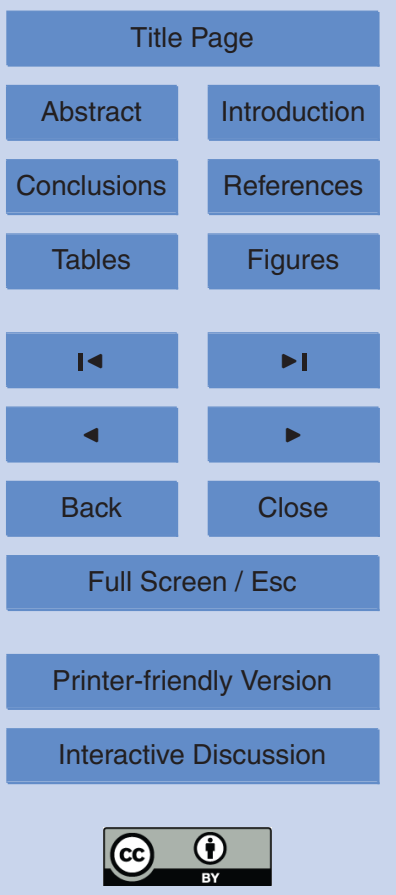


the bedrock beneath) is prevailing, indicating median-evident subsidence (interpreted by "c ${ }_{1}$ "-"cc" in Fig. 4). The deposit accumulation is dominated at the foot of slopes, and thus derived InSAR measurements demonstrate as mild uplifts again (interpreted by "d" and "dd" in Fig. 4). In addition, the time series of two typical CPs (marked by "A" and 5 " $\mathrm{B}$ " in Fig. 7) is further analyzed, as illustrated in Fig. 8. The seasonal variation is remarkable, revealing the influence of the Southeastern Asian monsoons. It also implies that the geomorphological process in the study site is dominant instead of the active layer and permafrost evolution in a relatively short 3.5-yr observation span. To make a summary, we found that physical movements along slopes are sophisticated in TP 10 region; more information with respect to topography (slope gradients and facing direction), geology (mantle composition and surface cover), hydrology (surface-subsurface runoff and permafrost ice-content melting) are required for the surface deformation monitoring (e.g. motion rates, directions and trends) as well as the causality interpretation (rainfall, the active layer and permafrost activities).

\subsection{Qinghai-Tibet railway}

The QTR project is a 100-yr grand plan; therefore its embankment instability needs to be well monitored to avoid potential geo-hazards. The embankment deformation surveillance has been covered by recent preliminary studies (Li et al., 2009; Zhang et al., 2010). In this investigation, the classical SB-InSAR is applied considering the correlation between perpendicular baselines and acquisition times of ALOS PALSAR (Samsonov, 2010); in such a way, the velocity rates noise can be further reduced primarily owing to the enhanced quality of interferograms using the small baseline strategy, as illustrated in Fig. 9a. Except for few uplifts due to proactive "cooling down" measures (Yu et al., 2008), see Fig. 9b, the surface subsidence along the embank25 ment of QTR is dominant, primarily in the range of $-25 \mathrm{~mm} \mathrm{yr}^{-1}$ to $-10 \mathrm{~mm} \mathrm{yr}^{-1}$. This is probably caused by the combination of the increased compression settlement, destroyed active layer as well as depressed soil heat release. The motion trend of the embankment along the QTR has been exploited by the improved Interferometric Point

\section{Surface deformation monitoring by InSAR over Tibet permafrost regions}

F. Chen and H. Lin

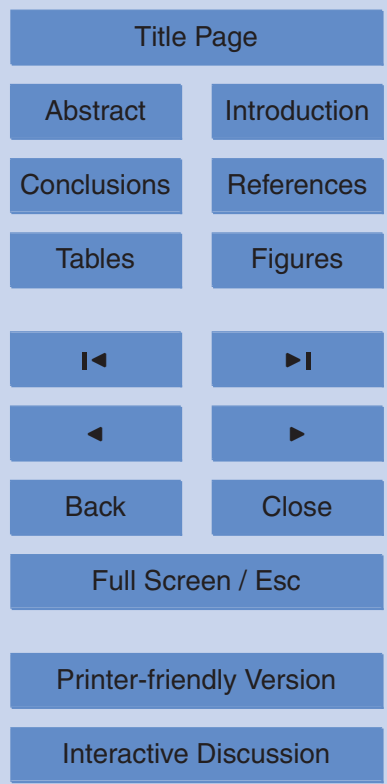


Target Analysis (IPTA) approach in our previous study (Chen et al., 2012b). Compared with the previous one, the signal-to-noise ratio of deformation rates in this investigation have been significantly improved, resulting in easy identification for potentially risky sections, which is indeed significant for the management of the QTR embankment.

\section{Conclusions}

In this study, taking the Beiluhe section, Qinghai, China as the experimental site, we examine the relationship of surface deformation, water balance, geomorphological process and anthropogenic activities through InSAR approaches. Apart from the probable tectonic activity, the SB-InSAR derived results indicate that the surface movement over 10 TP permafrost environment is still obvious, primarily in the range of $-30 \mathrm{~mm} \mathrm{yr}^{-1}$ to $-30 \mathrm{~mm} \mathrm{yr}^{-1}$ in LOS direction. In general, the uplifts often occur in the mountainous regions dominated by the slope processes; in contrast, the subsidence trends to occur in backslopes or WRIP regions with mild terrain. The main conclusions of this work can be summarized as follows.
1. Instead of PS points, the CP targets in the permafrost environment are prevalent; this phenomenon determines the feasibility of SB-InSAR. Totally $8025313 \mathrm{CPs}$ over the study site $\left(63 \times 45 \mathrm{~km}^{2}\right)$ are extracted with the temporal coherence threshold of 0.6 , that is, $2800 \mathrm{CPs} \mathrm{km}^{-2}$. Referring to the Figs. 1 and 3 , it is clear that the majority of land covers are identified as DS targets, except for the water body (Gulug Co lake, Beilu River) and sandy-bare ground around the Beiluhe valley because of the mirror scattering. The high density of DSs is jointly determined by the small baseline interferometric formation as well as L-band long wavelength of ALOS PALSAR data. In addition, the isolated interferogram clusters in the time domain (due to the corrective satellite orbit manoeuvre of PALSAR) further implies the suitability of the applied SB-InSAR for this case study.

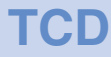

$6,4071-4099,2012$

\section{Surface deformation monitoring by InSAR over Tibet permafrost regions}

F. Chen and $\mathrm{H}$. Lin

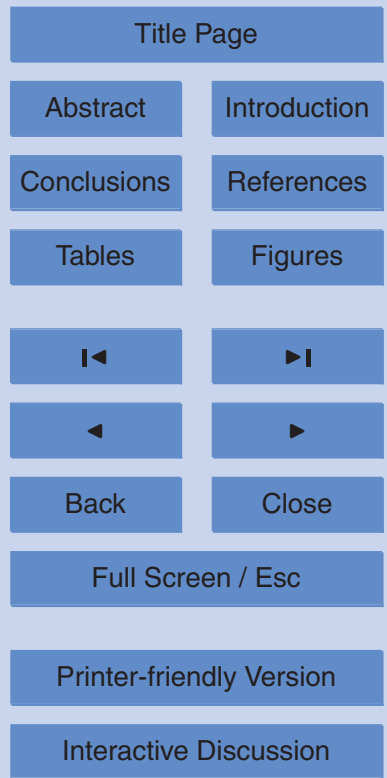


2. The movement of the overlaying active layer in slopes is more remarkable compared with other natural scenarios. This phenomenon is primarily determined by the erosion on unconsolidated surface triggered by heavy rainfalls in summer due to the Southeastern Asian monsoons. Furthermore, the motion trend indicates a notable seasonal variation. The slopes in this arid and cold region are covered by heavily weathered mantles with bare or sparse vegetation. The stability is vulnerable under the external driving-force from intense rainfalls, resulting in landslide occurrences. Generally, the transitional motion is dominant in the upper or median section, and then gradually transformed into rotational displacement due to deposits accumulation at the foot of slopes.

3. The water level variation of inland lakes in TP may be measured by InSAR or SB-InSAR when the horizontal water surface and cliff lakeshores allow a doublebounce refection of the transmitted radar signal back to the satellite. This technique has been successfully applied in wetlands (Lu et al., 2005; Wdowinski et al., 2008). Regarding to the Gulug Co inland lake, a north-east section of lakeshore with significant subsidence $\left(-50 \mathrm{~mm} \mathrm{yr}^{-1}\right.$ to $\left.-30 \mathrm{~mm} \mathrm{yr}^{-1}\right)$ is detected using the applied SB-InSAR method, implying the potential of space-observed InSAR for the water balance monitoring in TP. However, further investigations and validations are required to make a final confirmation.

4. The QTR and its neighborhood are suffering from much obvious surface subsidence than surrounding features (in the range of $-25 \mathrm{~mm} \mathrm{yr}^{-1}$ to $-10 \mathrm{~mm} \mathrm{yr}^{-1}$ ). This phenomenon reveals the human activity response to the evolution of the active layer as well as beneath permafrost: firstly, geological conditions as well as the land cover along the embankment have been changed during the construction, resulting in aggravated active layer erosion and then instability dominated by surface settlements. Secondly, the compression of the underlying permafrost soil has been accelerated from the downward pressure induced by the rocky foundation as well as running trains. Finally, the moisture-heat absorption and dispersion

\section{Surface deformation monitoring by InSAR over Tibet permafrost regions}

F. Chen and H. Lin

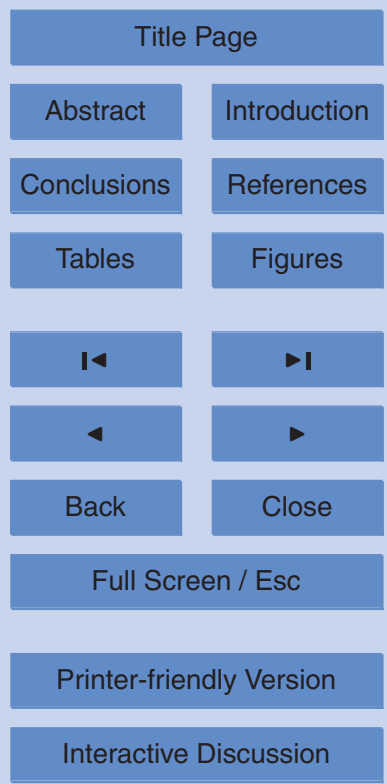


balance between the permafrost table/overlaid active layer and air has been destroyed; resulting in thaw subsidence due to heat accumulation. For more interpretations, interested readers can also refer to Chen et al. (2012b).

As described in Sect. 3, in order to derive interferograms with high quality, multi5 looking is applied at sacrifice of spatial resolution loss. More recently, several innovative methods (Ferretti et al., 2011; Hooper, 2008) have been proposed by synergistically using PS and DS to increase the spatial density of detected targets in natural scenarios and meanwhile preserve the original spatial resolution. Thereby, in near future, those novel methods will be further investigated in the TP study site, particularly using 10 high-resolution, newly-launched spaceborne SAR systems (e.g. TerraSAR-X, CosmoSkyMed and Radarsat-2) to extract more accurate seasonal/secular motions and corresponding time series, taking advantages of shorter revisit cycles (Bovenga et al., 2012).

Acknowledgements. This study has been supported by funding from the Research Grants cil of the HKSAR, China (450210), the Innovation and Technology Support Programme of HKSAR, China (ITS/152/11FP), the National Natural Science Foundation of China (41201455), and One Hundred Person Project of Centre for Earth Observation and Digital Earth, Chinese Academy of Sciences. We thank the Associate Editor and anonymous reviewers for their constructive and insightful comments. The digital elevation model of the investigated zone was 20 acquired through the SRTM archive. The original ALOS PALSAR data were provided by the Japan Aerospace Exploration Agency (JAXA).

\section{References}

Berardino, P., Fornaro, G., Lanari R., and Sansosti, E.: A new algorithm for surface deforamtion monitoring based on small baseline differential SAR interferograms, IEEE T. Geosci. Remote, 40, 2375-2383, 2002.

Bovenga, F., Wasowski, J., Nitti, D. O., Nutricato, R., and Chiaradia, M. T.: Using COSMO/SkyMed X-band and ENVISAT C-band SAR interferometry for landslides analysis, Remote Sens. Environ., 119, 272-285, 2012.

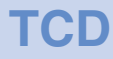

$6,4071-4099,2012$

\section{Surface deformation monitoring by InSAR over Tibet permafrost regions}

F. Chen and H. Lin

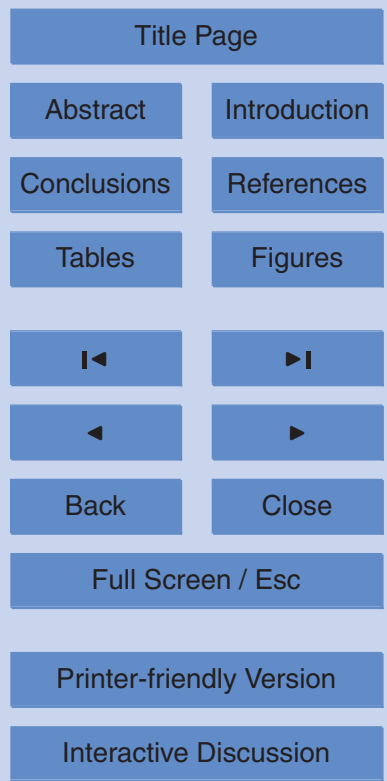


Cavalie, O., Lasserre, C., Doin M.-P., Peltzer, G., Sun, J., Xu, X., and Shen Z.-K.: Measurement of intersismic strain across the Haiyuan fault (Gansu, China), by InSA R, Earth Planet. Sc. Lett., 275, 246-257, 2008.

Chen, F. and Lin, H.: Multi-baseline differential SAR interferometry analysis of Lantau Highway, Hong Kong, using Envisat ASAR data, Remote Sens. Lett., 2, 167-173, 2011.

Chen, F., Lin, H., Yeung, K., and Cheng, S.: Detection of slope instability in Hong Kong based on multi-baseline differential SAR interferometry using ALOS PALSAR data, GISci. Remote Sens., 47, 208-220, 2010.

Chen, F., Lin, H., Zhang, Y., and Lu, Z.: Ground subsidence geo-hazards induced by rapid urbanization: implications from InSAR observation and geological analysis, Nat. Hazards Earth Syst. Sci., 12, 935-942, doi:10.5194/nhess-12-935-2012, 2012a.

Chen, F., Lin, H., Li, Z., Chen, Q., and Zhou, J.: Interaction between permafrost and infrastructure along the Qinghai-Tibet Railway detected via jointly analysis of C- and L-band small baseline SAR interferometry, Remote Sens. Environ., 123, 532-540, 2012b.

Colesanti, M.: A novel phase unwrapping method based on network programming, IEEE T. Geosci. Remote, 36, 813-821, 1998.

Ferretti, A., Prati, C., and Rocca, F.: Nonlinear subsidence rate estimation using persistent scatterers indifferential SAR interferometry, IEEE T. Geosci. Remote, 38, 2202-2212, 2000.

Ferretti, A., Fumagalli, A., Novali, F., Prati, C., Rocca, F., and Rucci, A.: A new algorithm for processing interferometric data-stacks: SqueeSAR, IEEE T. Geosci. Remote, 49, 3460-3470, 2011.

Guo, L. D. and Macdonald, R. W.: Source and transport of terrigenous organic matter in the upper Yukon River: evidence from isotope (delta C-13, Delta C-14, and delta N-15) composition of dissolved, colloidal, and particulate phases, Global Biogeochem. Cy., 20, GB2011, doi:10.1029/2005GB002593, 2006.

Hooper, A.: A multi-temporal InSAR method incorporating both persistent scatterer and small baseline approaches, Geophys. Res. Lett., 35, 1-5, 2008.

Hooper, A., Zebker, H., Segall, P., and Kampes, B.: A new method for measuring deformation on volcanoes and other natural terrains using InSAR persistent scatterers, Geophys. Res.

$30 \quad$ Lett., 31, L23611, doi:10.1029/2004GL021737, 2004.

Immerzeel, W., Stoorvogel, J., and Antle, J.: Can payments for ecosystem services secure the water tower of Tibet?, Agr. Syst., 96, 52-63, 2008.

\section{Surface deformation monitoring by InSAR over Tibet permafrost regions}

F. Chen and H. Lin

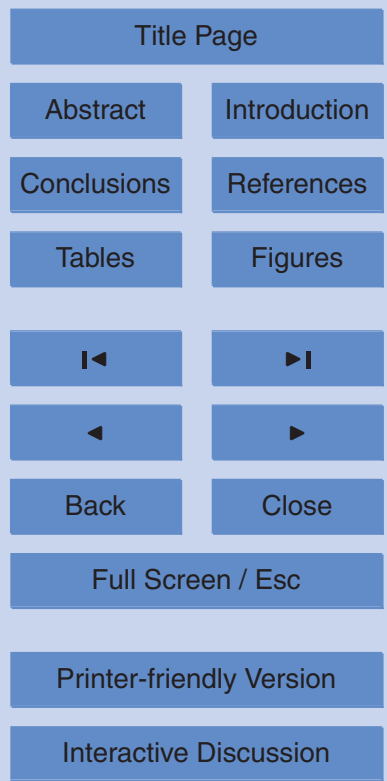


Ismail-Zadeh, A., Mouel, J. L. L., Soloviev, A., Tapponnier, P., and Vorovieva, I.: Numerical modeling of crustal block-and-fault dynamics, earthquakes and slip rates in the Tibet-Himalayan region, Earth Planet. Sc. Lett., 258, 465-485, 2007.

Jiang, L., Lin, H., Ma, J., Kong, B., and Wang, Y.: Potential of small-base SAR interferometry for 5 monitoring land subsidence related to underground coal fires: Wuda (Northern China) case study, Remote Sens. Environ., 115, 257-268, 2011.

Jin, H., Yu, Q., Wang, S., and Lu, L.: Changes in permafrost environments along the QinghaiTibet engineering corridor induced by anthropogenic activities and climate warming, Cold Reg. Sci. Technol., 53, 317-333, 2008.

10 Lanari, R., Mora, O., and Manunta, M.: A small-baseline approach for investigating deformations on full-resolution differential SAR interferograms, IEEE T. Geosci. Remote, 42, 13771386, 2004.

Li, S., Lai, Y., Zhang, M., and Dong, Y.: Study on long-term stability of Qinghai-Tibet Railway embankment, Cold Reg. Sci. Technol., 57, 139-147, 2009.

Lin, H., Chen, F., and Zhao, Q.: Land deformation monitoring using coherent targetneighborhood networking method combined with polarimetric information: a case study of Shanghai, China, Int. J. Remote Sens., 32, 2395-2407, 2011.

Liu, J., Wang, S., Yu, S., Yang, D., and Zhang, L.: Climate warming and growth of high-elevation inland lakes on the Tibetan Plateau, Global Planet. Change, 67, 209-217, 2009.

20 Liu, L., Zhang, T., and Wahr, J.: InSAR measurements of surface deformation over permafrost on the North Slope of Alaska, J. Geophys. Res.-Earth, 115, F03023, doi:10.1029/2009JF001547, 2010.

Liu, L., Schaefer, K., Zhang, T., and Wahr, J.: Estimating 1992-2000 average active layer thickness on the Alaskan North Slope from remotely sensed surface subsidence, J. Geophys. Res.-Earth, 117, F01005, doi:10.1029/2011JF002041, 2012.

Loveless, J. P. and Meade, B. J.: Partitioning of localized and diffuse deformation in the Tibetan Plateau from joint inversions of geologic and geodetic observations, Earth Planet. Sc. Lett., 303, 11-24, 2011.

Lu, Z., Crane, M., Kwoun, O. I., Wells, C., Swarzenski, C., and Rykhus, R.: C-band radar observes water level change in swamp forests, Eos T. Am. Geophys. Un., 86, 141-144, 2005.

Massonnet, D., Rossi, M., Carmona, C., Adragna, F., Peltzer, G., Feigl, K., and Rabaute, T.: The displacement field of the Landers earthquake mapped by radar interferometry, Nature, 364, 138-142, 1993.

\section{Surface deformation monitoring by InSAR over Tibet permafrost regions}

F. Chen and H. Lin

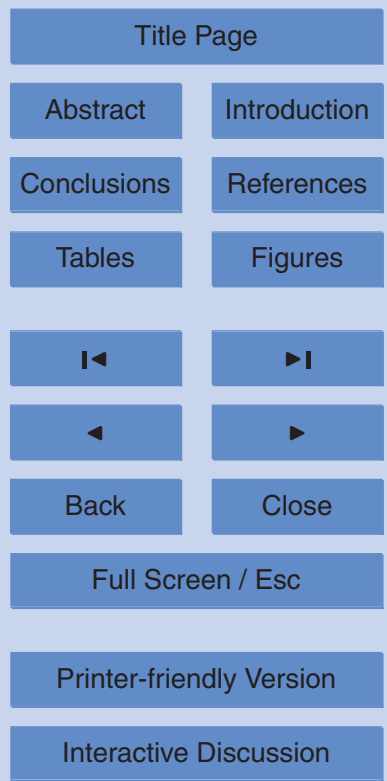


Monastersky, R.: Permafrost science heats up in the United States, Nature News, 19122011, doi:10.1038/nature.2011.9681, 2011.

Niu, F., Lin, Z., Liu, H., and Lu, J.: Characteristics of thermokarst lakes and their influence on permafrost in Qinghai-Tibet Plateau, Geomorphology, 132, 222-233, 2011.

5 Qiao, X., Yang, S., Du, R., Ge, L., and Wang, Q.: Coseismic slip from the 6 October 2008, Mw6.3 Damxung Earthquake, Tibetan Plateau, constrained by InSAR observations, Pure Appl. Geophys., 168, 1749-1758, 2011.

Rykhus, R. P. and Lu, Z.: InSAR detects possible thaw settlement in the Alaskan Arctic Coastal Plain, Can. J. Remote Sens., 34, 100-112, 2008.

10 Samsonov, S.: Topographic correction for ALOS PALSAR interferometry, IEEE T. Geosci. Remote, 48, 3020-3027, 2010.

Short, N., Brisco, B., Couture, N., Pollard, W., Murnaghan, K., and Budkewitsch, P.: A comparison of TerraSAR-X, RADARSAT-2 and ALOS-PALSAR interferometry for monitoring permafrost environments, case study from Herschel Island, Canada, Remote Sens. Environ., 15 155, 3491-3506, 2011.

Wdowinski, S., Kim, S. W., Amelung, F., Dixon, T. H., Miralles-Wilhelm, F., and Sonenshein, R.: Space-based detection of wetlands' surface water level changes from L-band SAR interferometry, Remote Sens. Environ., 112, 681-696, 2008.

Wang, G., Li, Y., Wang, Y., and Wu, Q.: Effects of permafrost thawing on vegetation and soil carbon pool losses on the Qinghai-Tibet Plateau, China, Geoderma, 143, 143-152, 2008.

Wang, G., Hu, H., and Li, T.: The influence of freeze-thaw cycles of active soil layer on surface runoff in a permafrost watershed, J. Hydrol., 375, 438-449, 2009a.

Wang, G., Li, S., Hu, H., and Li, Y.: Water regime shifts in the active soil layer of the QinghaiTibet Plateau permafrost region, under different levels of vegetation, Geoderma, 149, 280$25289,2009 b$.

Wu, Q., Jiang, G., and Zhang, P.: Assessing the permafrost temperature and thickness conditions favorable for the occurrence of gas hydrate in the Qinghai-Tibet Plateau, Energ. Convers. Manage., 51, 783-787, 2010.

Xu, B. Q., Cao, J. J., Hansen, J., Yao, T. D., Joswia, D. R., and Wang, N. L.: Black soot and the 30 survival of Tibetan glaciers, P. Natl. Acad. Sci. USA, 106, 22114-22118, 2009.

Yang, M., Wang, S., Yao, T., Gou, X., Lu, A., and Guo, X.: Desertification and its relationship with permafrost degradation in Qinghai-Xizang (Tibet) plateau, Cold Reg. Sci. Technol., 39, 47-53, 2004.

\section{Surface deformation monitoring by InSAR over Tibet permafrost regions}

F. Chen and H. Lin

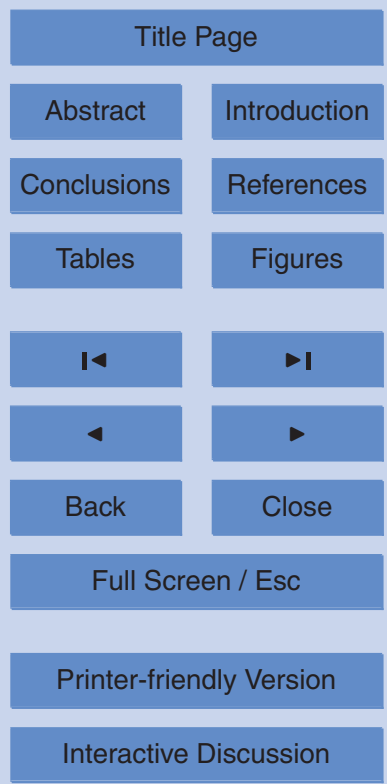


Yu, Q., Niu, F., Pan, X., Bai, Y., and Zhang, M.: Investigation of embankment with temperaturecontrolled ventilation along the Qinghai-Tibet Railway, Cold Reg. Sci. Technol., 53, 193-199, 2008.

Zhang, B., Zhang, J., and Qin, Y.: Investigation for the deformation of embankment underlain by warm and ice-rich permafrost, Cold Reg. Sci. Technol., 60, 161-168, 2010.

Zhang, G., Xie, H., Kang S., Yi, D., and Ackley, S.: Monitoring lake level changes on the Tibetan Plateau using ICESat altimetry data (2003-2009), Remote Sens. Environ., 115, 1733-1742, 2011.

\section{Surface deformation monitoring by InSAR over Tibet permafrost regions}

F. Chen and $\mathrm{H}$. Lin

Title Page

Abstract

Conclusions

Tables

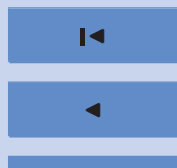

Back
Introduction

References

Figures

$\rightarrow$ I

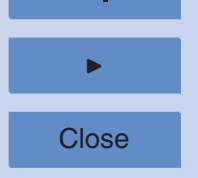

Full Screen / Esc

Printer-friendly Version 
Table 1. ALOS PALSAR data. The acquisition of 26 September 2009 image was selected as the reference for coregistration.

\begin{tabular}{rlcll}
\hline Acquisition time & Polarization & $\begin{array}{l}\text { Perpendicular } \\
\text { baseline }(\mathrm{m})\end{array}$ & $\begin{array}{l}\text { Temporal } \\
\text { baseline (days) }\end{array}$ & Doppler Centroid \\
\hline 21 Jun 2007 & $\mathrm{HH} / \mathrm{HV}$ & 544.10 & -828 & 52.11 \\
6 Aug 2007 & $\mathrm{HH} / \mathrm{HV}$ & 819.21 & -782 & 32.98 \\
21 Sep 2007 & $\mathrm{HH} / \mathrm{HV}$ & 675.74 & -736 & 10.40 \\
22 Dec 2007 & $\mathrm{HH}$ & 1169.09 & -644 & 29.33 \\
6 Feb 2008 & $\mathrm{HH}$ & 1940.73 & -598 & 23.63 \\
23 Mar 2008 & $\mathrm{HH}$ & 1992.35 & -552 & 38.55 \\
8 Aug 2008 & $\mathrm{HH} / \mathrm{HV}$ & -2737.63 & -414 & -34.54 \\
23 Sep 2008 & $\mathrm{HH} / \mathrm{HV}$ & -1929.62 & -368 & 47.97 \\
8 Nov 2008 & $\mathrm{HH}$ & -1757.57 & -322 & 20.20 \\
24 Dec 2008 & $\mathrm{HH}$ & -1633.35 & -276 & 25.54 \\
8 Feb 2009 & $\mathrm{HH}$ & -1011.88 & -230 & 44.22 \\
26 Jun 2009 & $\mathrm{HH} / \mathrm{HV}$ & -298.55 & -92 & 51.82 \\
26 Sep 2009 & $\mathrm{HH} / \mathrm{HV}$ & 0 & 0 & 24.05 \\
27 Dec 2009 & $\mathrm{HH}$ & 548.37 & 92 & 18.68 \\
11 Feb 2010 & $\mathrm{HH}$ & 1097.01 & 138 & 38.44 \\
29 Jun 2010 & $\mathrm{HH} / \mathrm{HV}$ & 1535.55 & 276 & 67.46 \\
14 Aug 2010 & $\mathrm{HH} / \mathrm{HV}$ & 1927.2378 & 322 & 54.74 \\
29 Sep 2010 & $\mathrm{HH} / \mathrm{HV}$ & 2192.90 & 368 & 72.23 \\
30 Dec 2010 & $\mathrm{HH}$ & 2410.26 & 460 & 34.27 \\
\hline
\end{tabular}

\section{6, 4071-4099, 2012}

\section{Surface deformation monitoring by InSAR over Tibet permafrost regions}

F. Chen and H. Lin

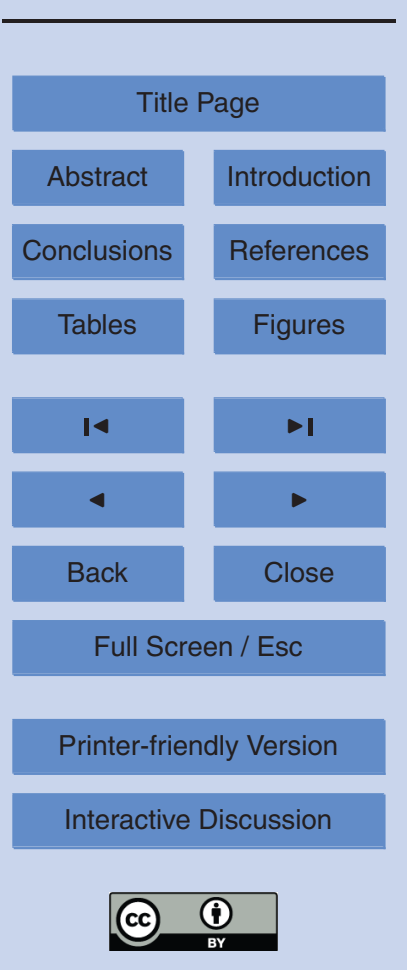




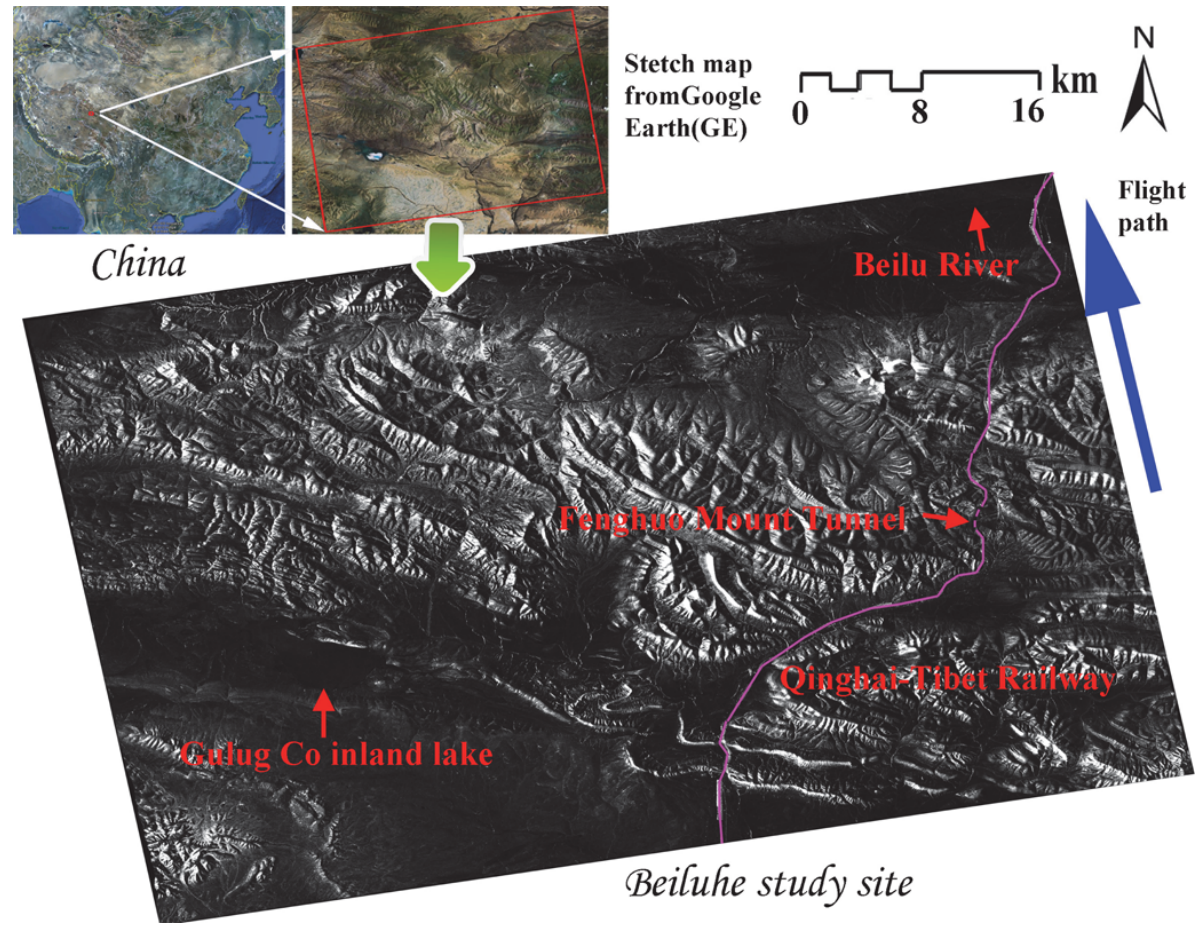

Fig. 1. Location of Beiluhe study site, Qinghai province, China. The Qinghai-Tibet Railway is marked by the pink line (dotted section indicates the Fenghuo Mount Tunnel). ALOS PALSAR flight path is marked by the blue arrow, and the optical inset images are from the Google Earth (GE).

\section{TCD}

$6,4071-4099,2012$

\section{Surface deformation monitoring by InSAR over Tibet permafrost regions}

F. Chen and $\mathrm{H}$. Lin

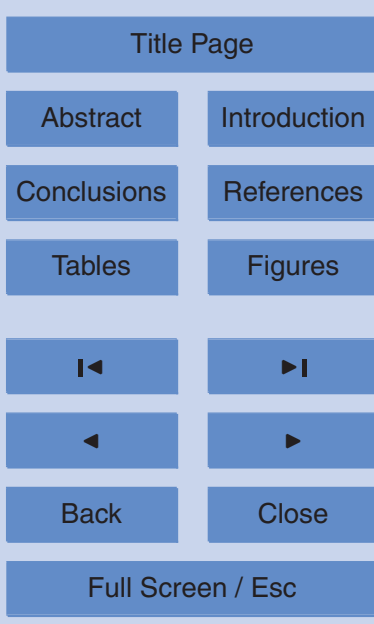

Printer-friendly Version

Interactive Discussion 
Time-Position Plot

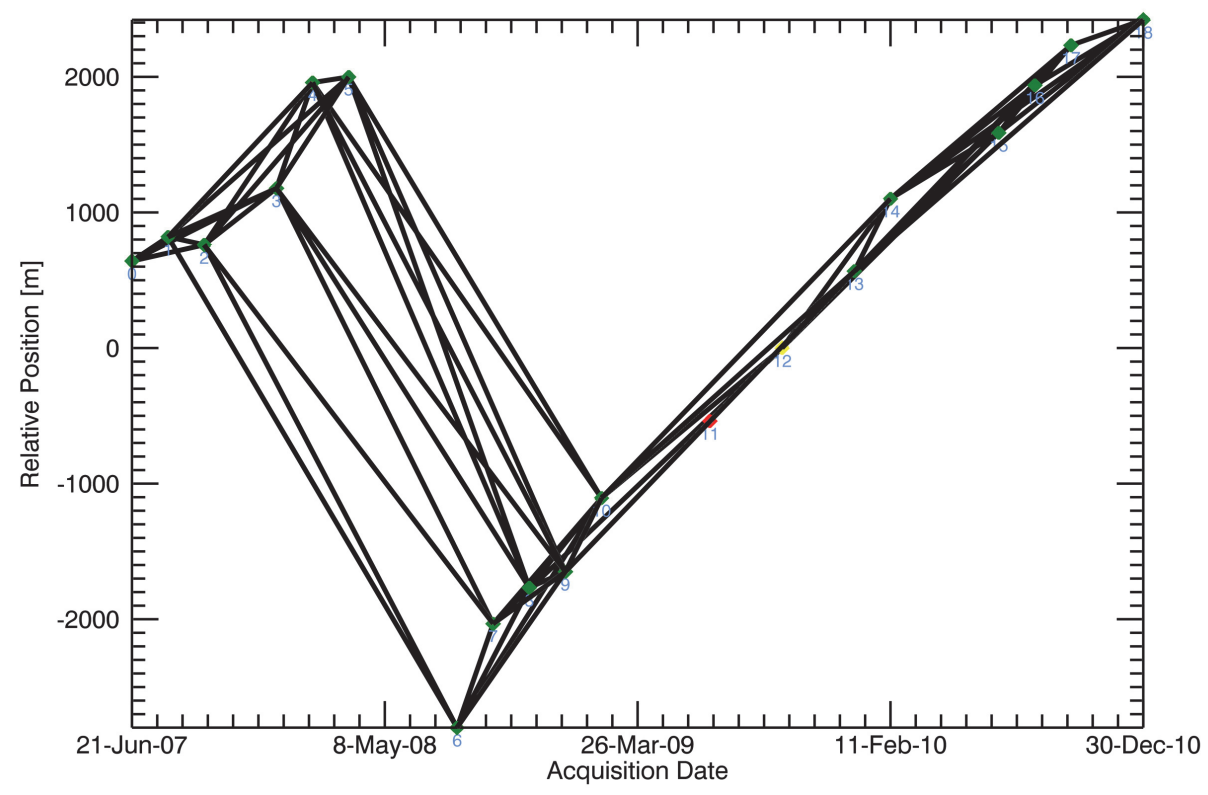

Fig. 2. Spatial-temporal distribution of interferogram formation based on the small baseline constraint. It is clear that the perpendicular baselines are correlated with the acquisition time. The number 12 image marked in yellow is the reference image acquired on 26 September 2009 for the dataset co-registration. The image marked in red is discarded because of its evident atmospheric disturbance.

\section{TCD}

6, 4071-4099, 2012

\section{Surface deformation monitoring by InSAR over Tibet permafrost regions}

\section{F. Chen and H. Lin}

\section{Title Page}

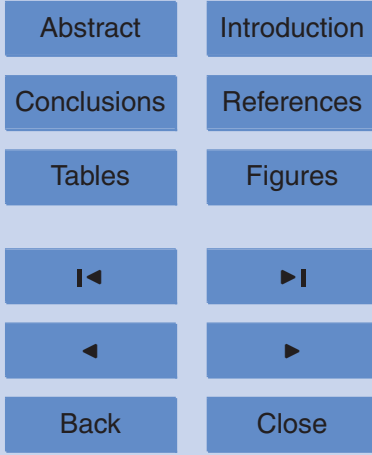

Full Screen / Esc

Printer-friendly Version

Interactive Discussion 


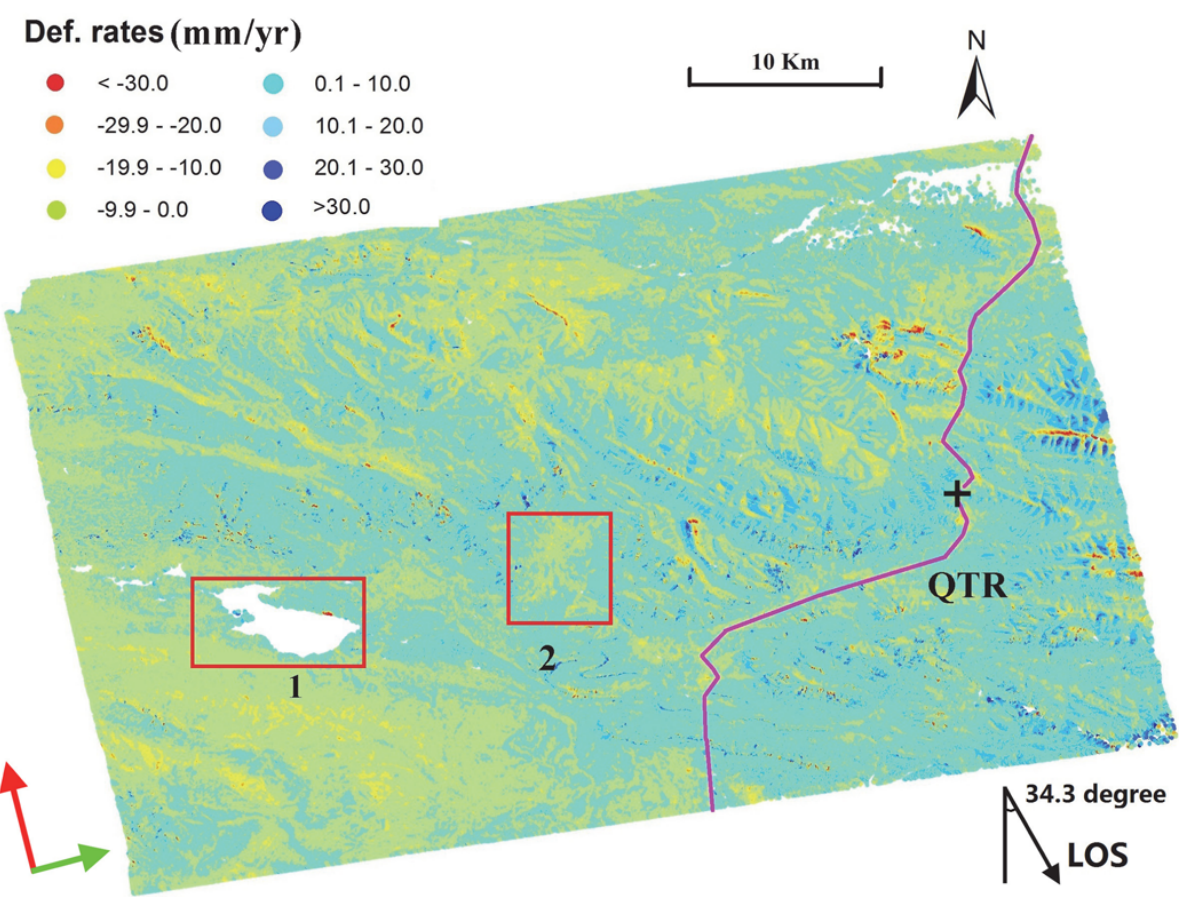

Fig. 3. SB-InSAR derived surface displacement rates over Beiluhe TP permafrost environment in LOS direction. Sub-region of "1" and "2" represent the Gulug Co inland lake and a slope in Fenghuo Mount, respectively. The Qinghai-Tibet Railway is marked by the pink line. The cross marks the location of leveling data (nearby the Fenghuo Mount Tunnel frontier) for SB-InSAR results validation. The satellite was travelling in the direction of the red arrow and looking in the direction of the green arrow.
6, 4071-4099, 2012

\section{Surface deformation monitoring by InSAR over Tibet permafrost regions}

F. Chen and $\mathrm{H}$. Lin

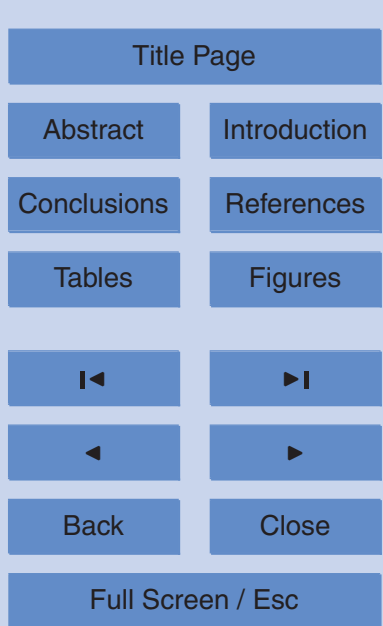

Printer-friendly Version

Interactive Discussion 


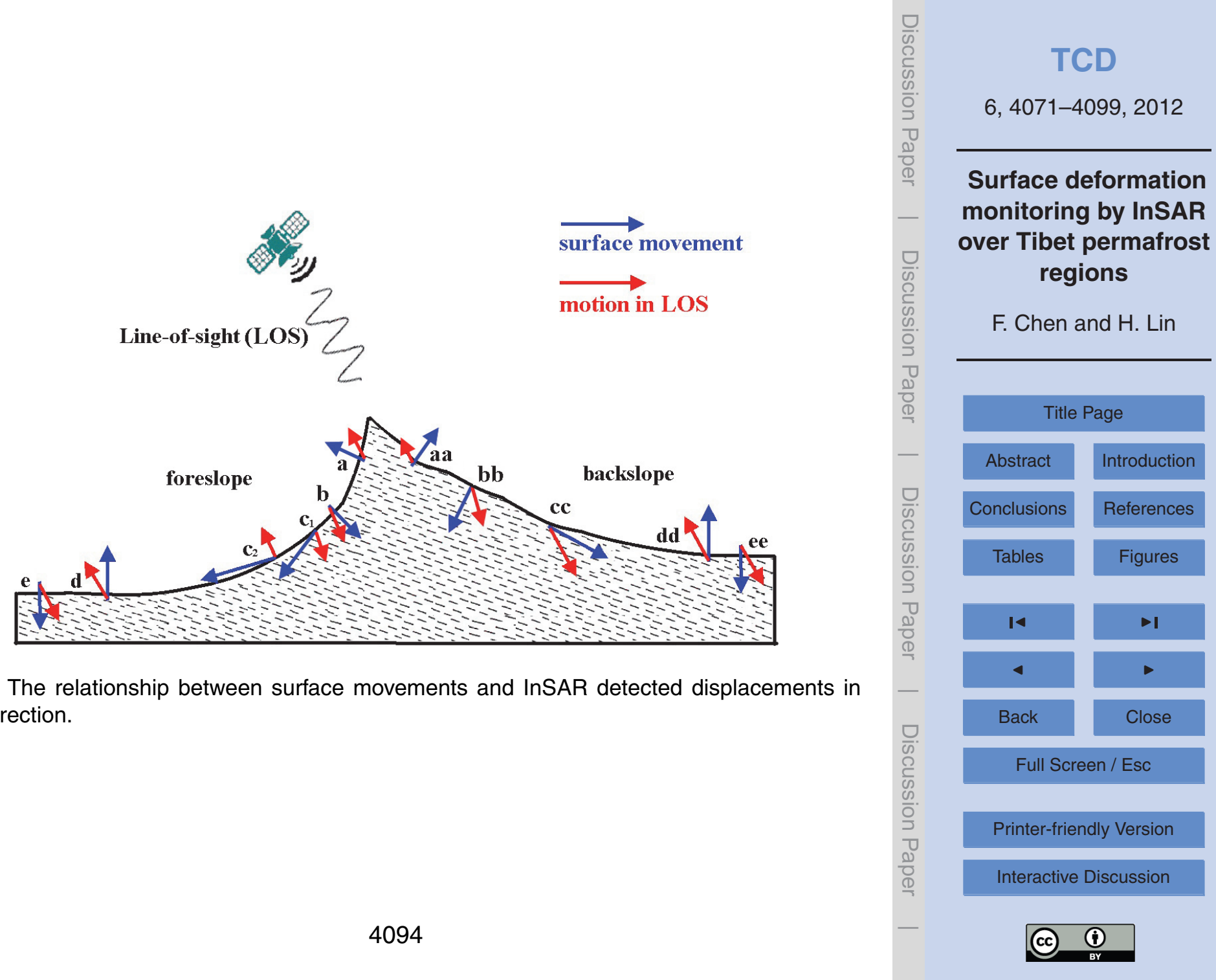




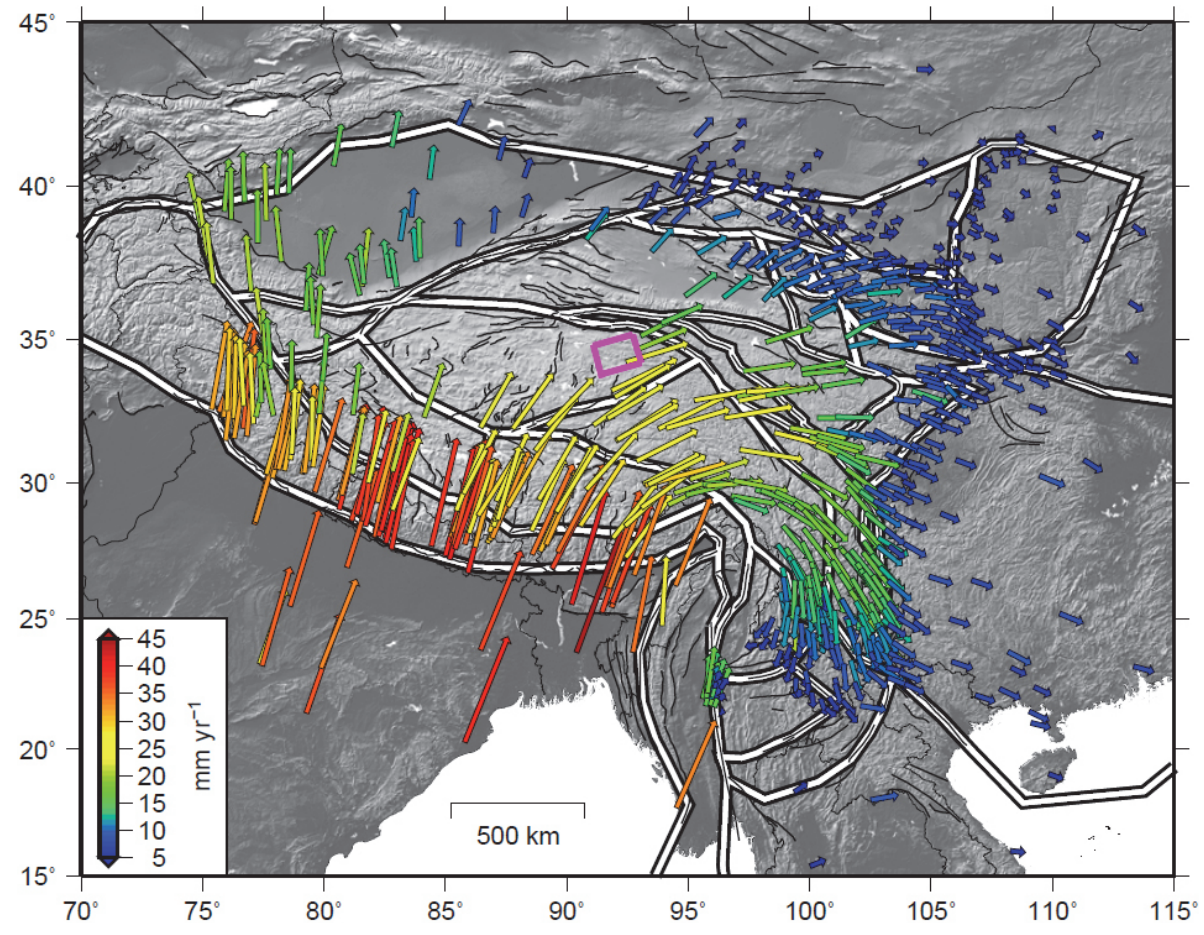

Fig. 5. Nominally interseismic GPS velocities expressed relative to a stable Eurasian reference frame covering the TP (the original version is from Loveless and Meade, 2011). The Beiluhe section is highlighted by the pink rectangle.

\section{TCD}

6, 4071-4099, 2012

\section{Surface deformation monitoring by InSAR over Tibet permafrost regions}

F. Chen and $\mathrm{H}$. Lin

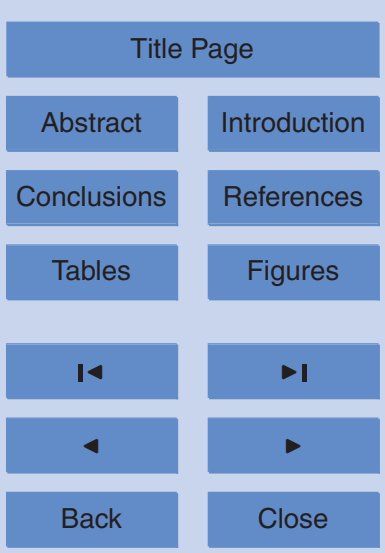

Full Screen / Esc

Printer-friendly Version

Interactive Discussion 


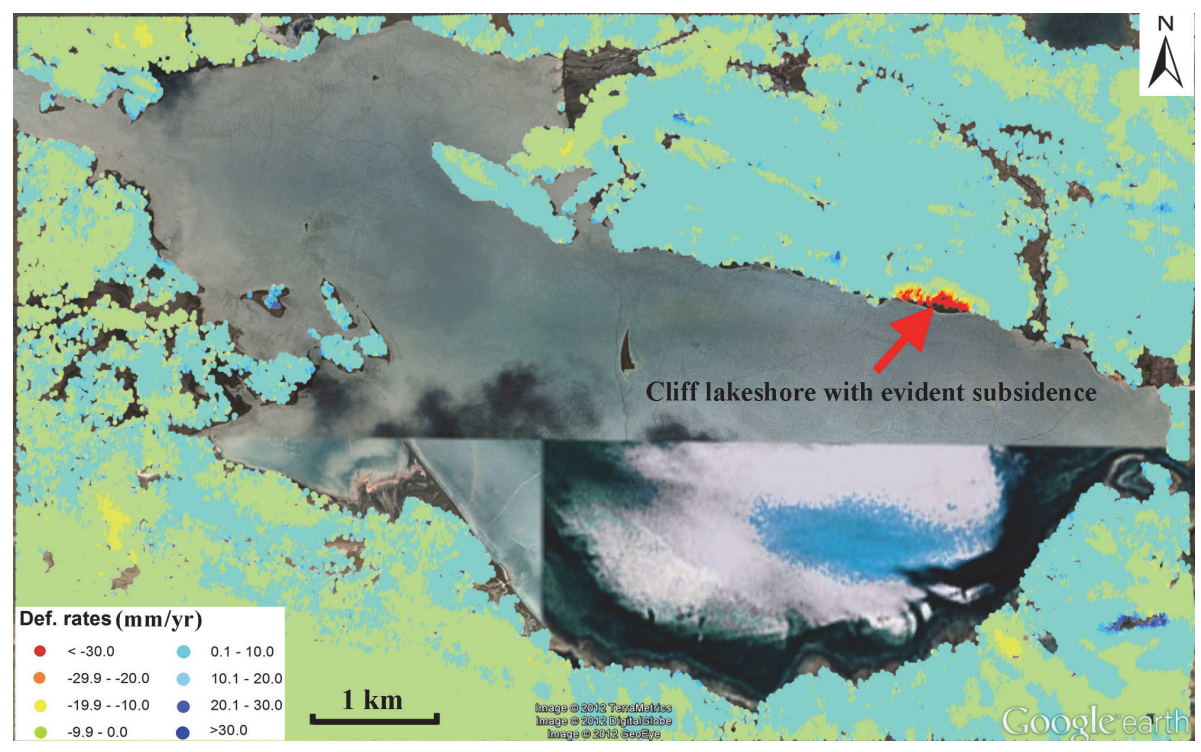

Fig. 6. Surface deformation annual rates surrounding the Gulug Co inland lake overlapped on the optical image from Google Earth (GE). Severe subsidence is detected in a section with cliff lakeshore, as marked by the red arrow (note that there is no InSAR signature in the lake).

\section{TCD}

6, 4071-4099, 2012

\section{Surface deformation monitoring by InSAR over Tibet permafrost regions}

F. Chen and $\mathrm{H}$. Lin

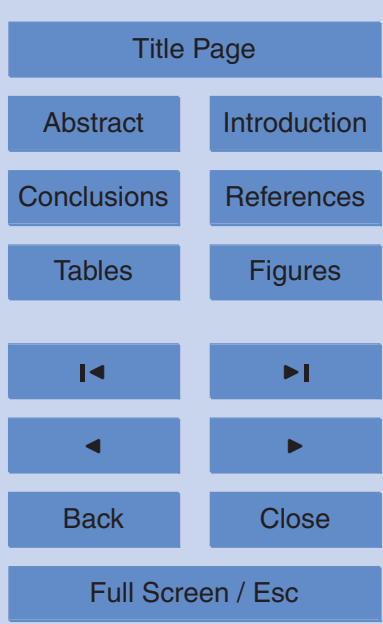

Printer-friendly Version

Interactive Discussion 

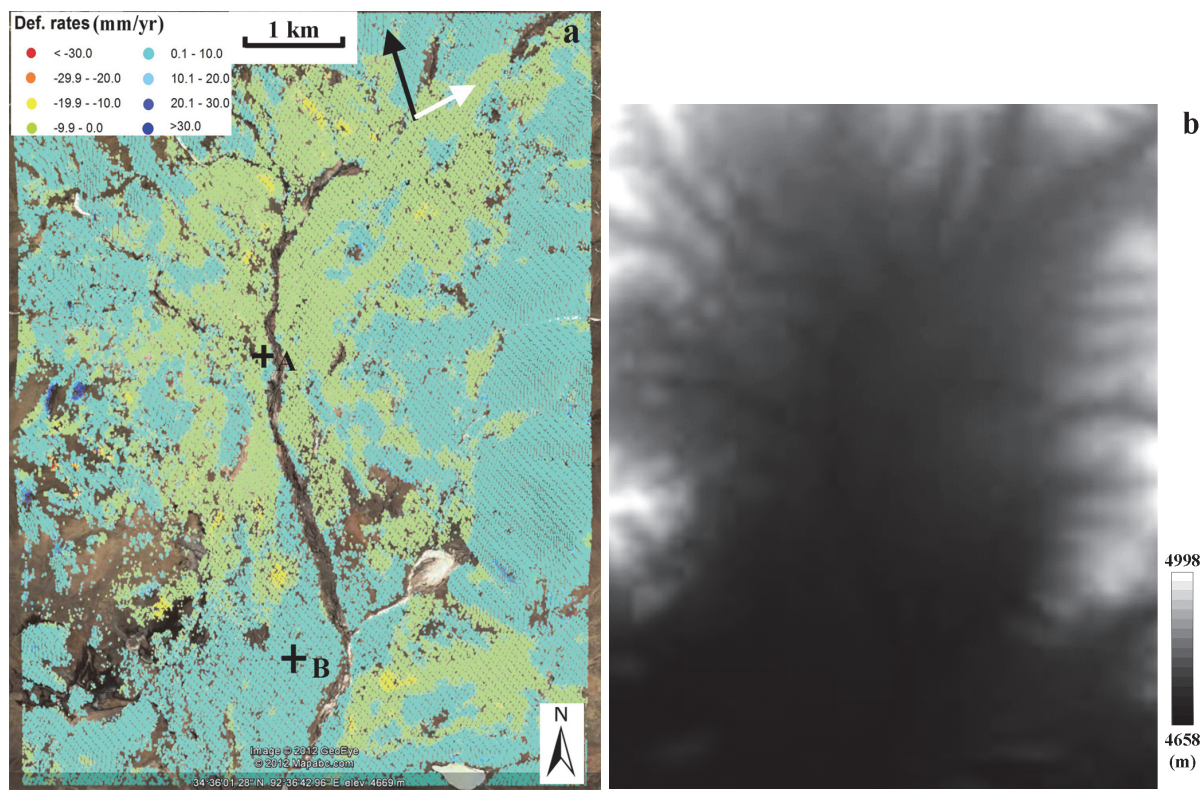

Fig. 7. Different motion mechanisms can be discriminated by InSAR measurements along a mountainous area with slopes. (a) Surface deformation annual rates overlapped on the optical image from Google Earth (GE); crosses "A" and "B" indicate two CP targets for the time series analysis, the black and white arrows mark the satellite travelling and looking directions. (b) Relief shaded DEM.

\section{TCD}

6, 4071-4099, 2012

\section{Surface deformation monitoring by InSAR over Tibet permafrost regions}

F. Chen and $\mathrm{H}$. Lin

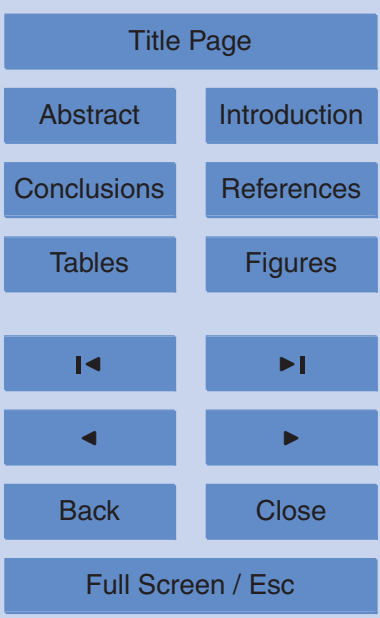

Printer-friendly Version

Interactive Discussion 


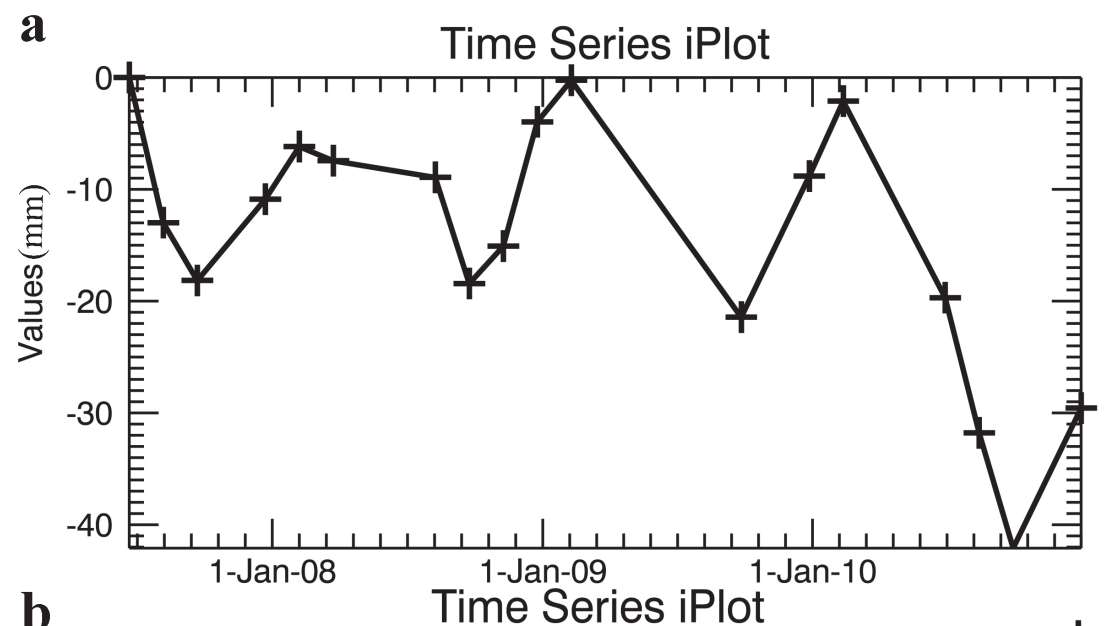

6, 4071-4099, 2012

\section{Surface deformation monitoring by InSAR over Tibet permafrost regions}

F. Chen and H. Lin

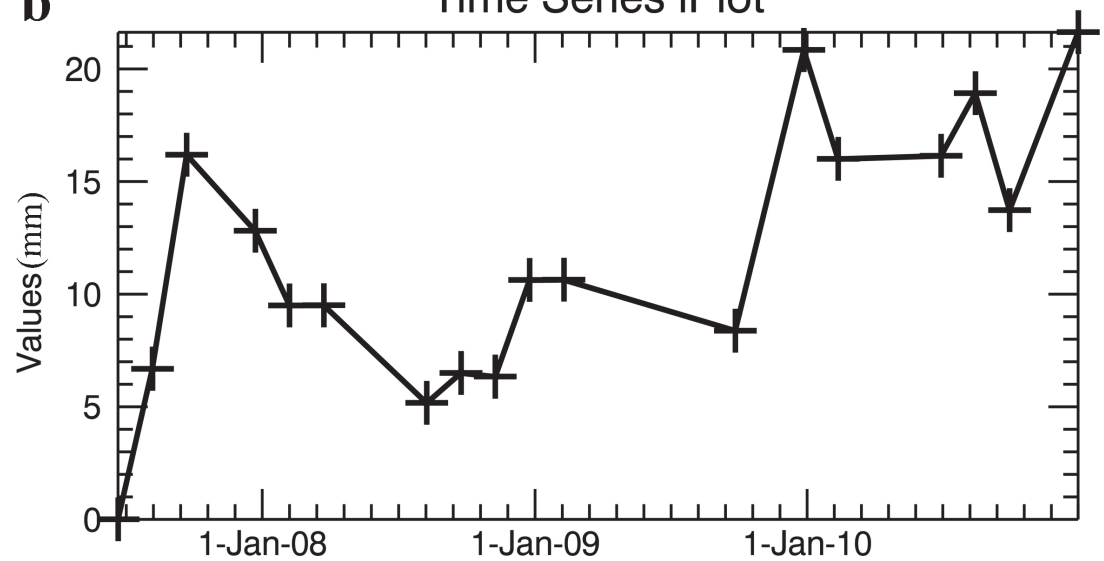

Title Page

Abstract

Conclusions

Tables

14

4

Back

Full Screen / Esc

Printer-friendly Version

Interactive Discussion
Fig. 8. Displacement time series of two typical CP targets (marked by crosses in Fig. 7); (a) the subsidence, (b) the uplift. The seasonal variation is obvious. 

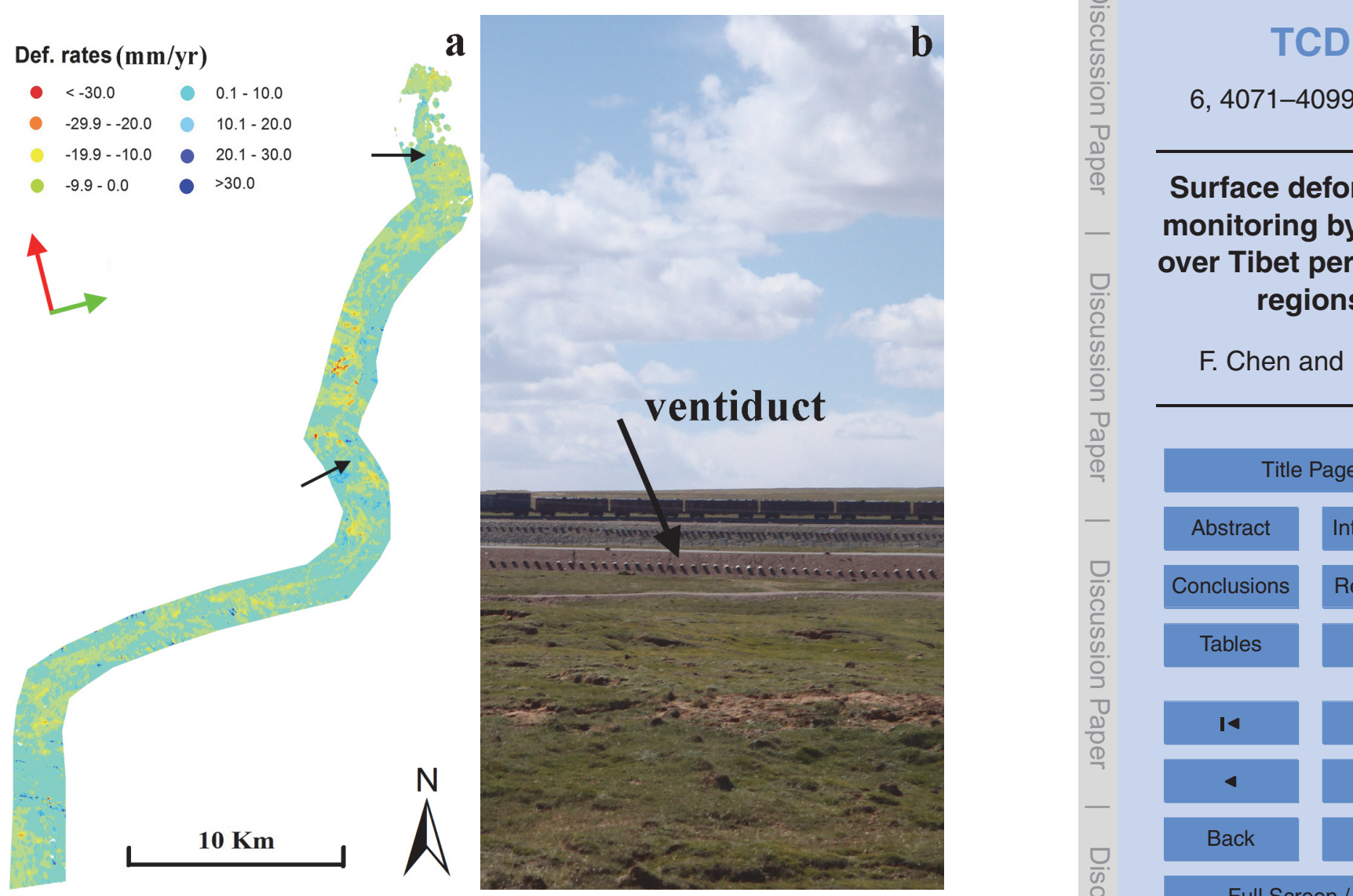

6, 4071-4099, 2012

\section{Surface deformation monitoring by InSAR over Tibet permafrost regions}

F. Chen and $\mathrm{H}$. Lin

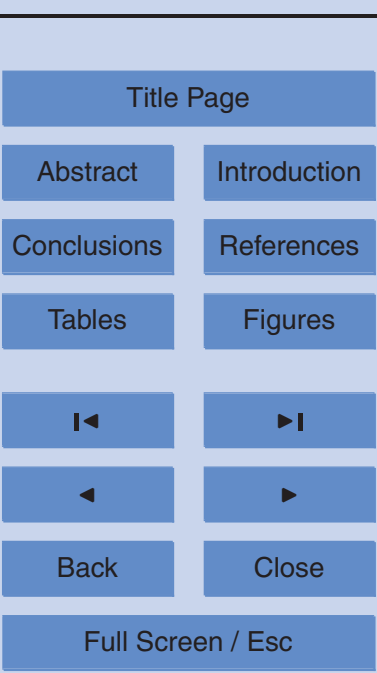

Fig. 9. (a) Surface deformations along the embankment of QTR in Beiluhe section, Qinghai, China. The red and green arrows mark the satellite travelling and looking directions. The uplift patches due to cooling measures are marked by black arrows. (b) Cooling-down measure of ventiduct along the embankment of QTR. 